\title{
DEVELOPMENT AND VALIDATION OF FIRST ORDER DERIVATIVE SPECTROPHOTOMETRIC METHOD FOR SIMULTANEOUS ESTIMATION OF TERBUTALINE AND ETOPHYLLINE
}

\author{
Yash S. Nandwani, Santosh V. Gandhi*, Shreeyash R. Tapale \\ AISSMS College of Pharmacy, Kennedy Road, Pune-411 001, India. \\ *Corresponding author e-mail: santoshvgandhi@rediffmail.com
}

Received: 12 February 2017

Revised: 5 March 2017

Accepted: 10 March 2017

\begin{abstract}
:
The present work describe simple, sensitive, rapid, accurate, precise and economical first derivative spectrophotometric (zero crossing) method for the simultaneous determination of Terbutaline and Etophylline in fixed dose combination. The first order derivative absorption at $280 \mathrm{~nm}$ (zero cross point for Etophylline) and $272.5 \mathrm{~nm}$ (zero cross point for Terbutaline) was used for Terbutaline and Etophylline determination, respectively. The linearity of Terbutalineand Etophyllinewas observed in the range of 5-30 $\mu \mathrm{g} / \mathrm{ml}$ with correlation coefficient $\left(\mathrm{r}^{2}\right)$ of 0.9981 and 0.9979 , respectively.The mean \% recoveries were found to be in the range of $100.09 \%$ and $96.86 \%$ for Terbutaline and Etophylline, respectively. The method was validated as per ICH Q2(R1) guidelines.
\end{abstract}

Key words: Derivative spectroscopy, Terbutylline, Etophylline, Validation.

\section{INTRODUCTION:}

Terbutaline (TER) is 5-[2-(tert-butylamino)1-hydroxyethyl] benzene-1,3-diol (Fig 1 a). TER is selective beta 2 adrenergic bronchodilator[1]. Literature survey reveals UV [2], HPLC [3-4] methods for estimation of TER in alone and in combination with other drugs. Etophylline (ETO) is chemically $1 \mathrm{H}$ Purine-2,6-dione, 3,7- dihydro-7-(2hydroxyetyl)-1,3- dimethyl (Fig 1 b). ETO is the hydroxyl ethyl ester of theophylline. It belongs to xanthine group of drugs. It acts on respiratory tract by inhibiting phosphodiesterase, which degrades cyclic nucleotides, hence increased amount of intra cellular CAMP molecule causing smooth muscle relaxation [5]. Literature survey reveals HPLC [6-7] and visible spectrophotometry [8] methods for determination of ETO with other drugs in combination.ETO is not official in any www.ijapbjournal.com pharmacopeia while TER is official in IP and USP [9-10].

The purpose of present work describes the development of a simple, precise, accurate and economic spectro-photometricmethod for the simultaneous estimation of TER and ETO in fixed dose combination. As there is no reported method on the above combination,this work was undertaken. The developed method was validated in accordance with ICH guidelines and successfully employed for the assay of TER and ETO in fixed dose combination.

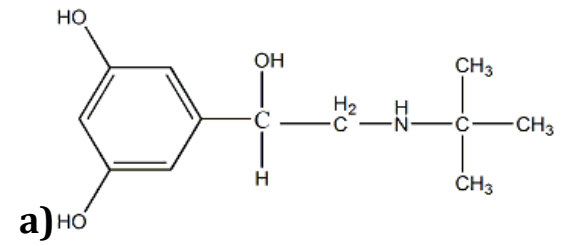


b)

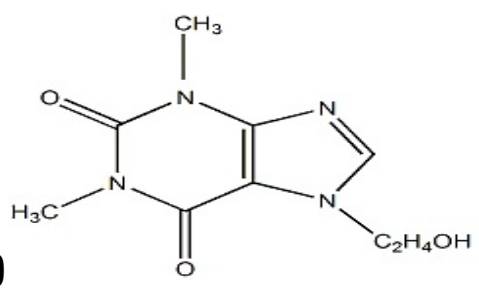

Fig. 1: Structure of a) Terbutaline and

b) Etophylline

\section{MATERIALS AND METHODS}

\subsection{Instrumentation}

A double beam UV/Visible spectrophotometer (Jasco V550, Japan) with matching pair of $1 \mathrm{~cm}$ quartz cells was used to record all spectra. Band width was kept 2 $\mathrm{nm}$ and scanning was carried at speed of 400 $\mathrm{nm} / \mathrm{min}$. Spectra manager software (version 1.53.01) was used to do all data collection. MS-Excel was used to do all statistical calculations.

\subsection{Reagents and Materials}

TER and ETO bulk powder were kindly gifted by Himalaya Meditek Pvt. Ltd., Dehradun, India. Bulk drug were used without further purification. Methanol AR Grade was procured from S. D. Fine Chemicals Ltd., Mumbai, India.

\subsection{Preparation of standard stock solution}

Stock solution of TER and ETO were prepared by dissolving accurately weighed $10 \mathrm{mg}$ of standard drugs in $10 \mathrm{ml}$ of methanol, separately. The concentration of TER and ETO were $1000 \mu \mathrm{g} / \mathrm{ml}$ from which further $1 \mathrm{ml}$ was pipetted and diluted to $10 \mathrm{ml}$ to achieve concentration of $100 \mu \mathrm{g} / \mathrm{ml}$ of TER and ETO, respectively.

\subsection{Methodology}

The working standard solutions of TER and ETO were prepared separately in methanol having concentration of $10 \mu \mathrm{g} / \mathrm{ml}$ by dilution of stock solution. They were scanned in the wavelength range of 200-400 $\mathrm{nm}$ against solvent methanol as blank. The absorption spectra thus obtained were derivatised to first order. From the overlain spectra of both the drugs (Fig. 2) wavelengths selected for quantitation were $280 \mathrm{~nm}$ for ETO (zero cross point of TER) and $272.5 \mathrm{~nm}$ for TER (zero cross point of ETO).

\subsection{Validation of proposed method}

The proposed method was validated according to the ICH Q2 (R1) guidelines.

\subsubsection{Linearity}

The calibration curves were plotted over a concentration range of $5-30 \mu \mathrm{g} / \mathrm{ml}$ for TER and ETO. Accurately measured standard stock solutions (Concentration $100 \mu \mathrm{g} / \mathrm{ml}$ ) of both drugs $(0.5,1.0,1.5,2.0,2.5$ and $3.0 \mathrm{ml})$ were transferred to a series of $10 \mathrm{ml}$ of volumetric flasks and diluted to the mark with methanol. First-order derivative absorbance (D1) was measured at $272.5 \mathrm{~nm}$ for TER and $280 \mathrm{~nm}$ for ETO. The calibration curves were constructed by plotting absorbances versus concentrations and the regression equations were calculated. The overlain first derivative spectra of TER and ETO (5-30 $\mu \mathrm{g} / \mathrm{ml}$ each) in their linear range is given in Fig. 3. The absorbance data for calibration graph is given in Table 1 and calibration graph in Fig. 4 and Fig. 5. 


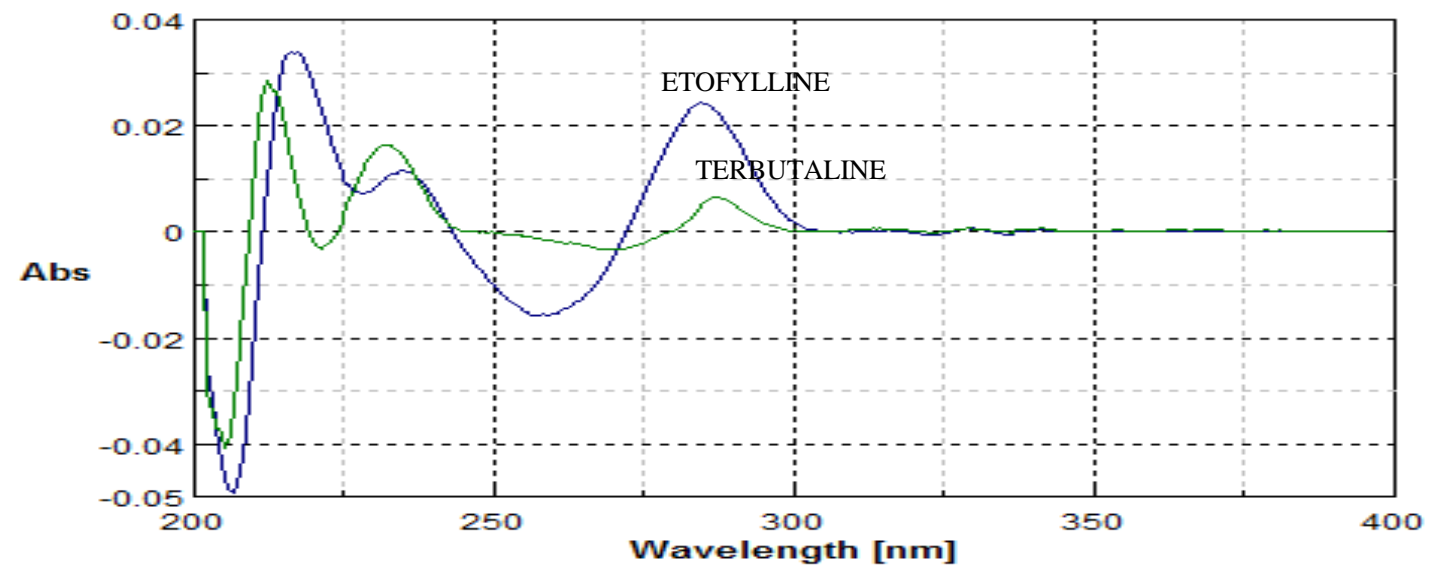

Fig. 2: Overlaid first derivative spectra of TER $(10 \mu \mathrm{g} / \mathrm{ml})$ and ETO $(10 \mu \mathrm{g} / \mathrm{ml})$

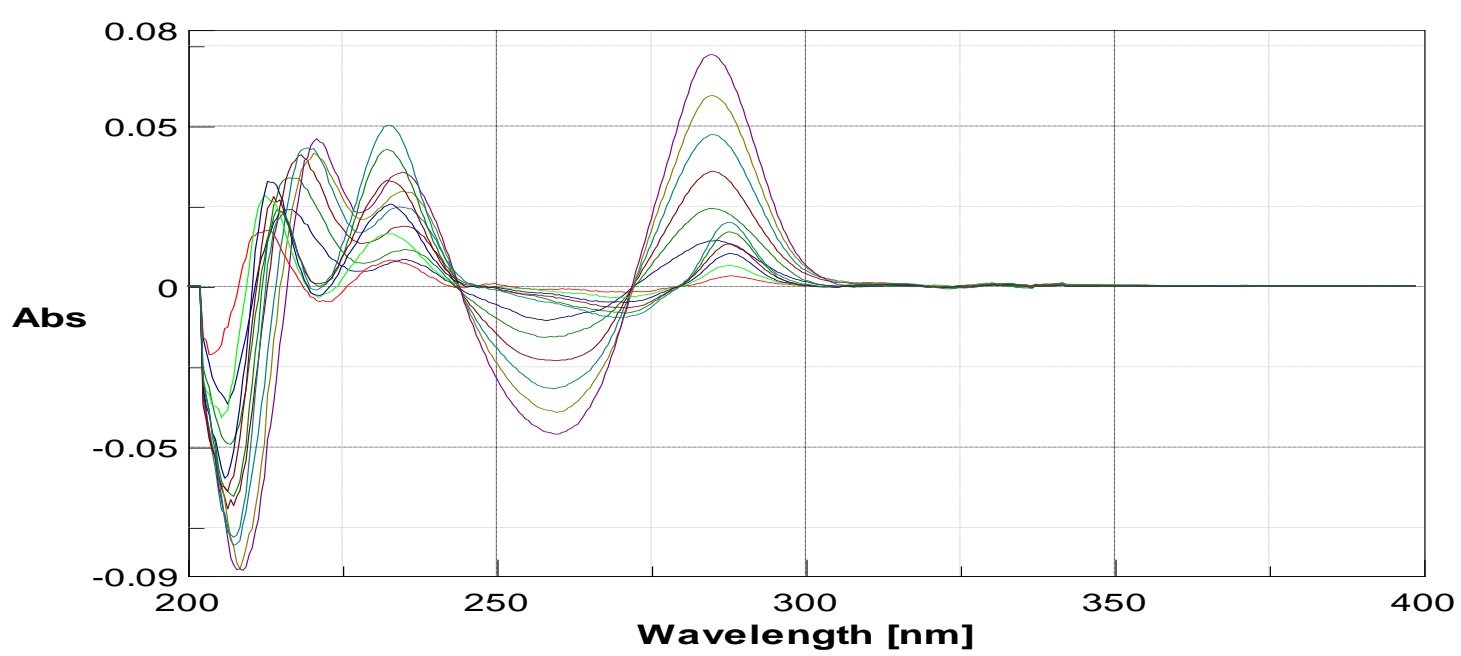

Fig. 3: Overlain first derivative spectra of TER and ETO $(5-30 \mu \mathrm{g} / \mathrm{ml}$ each $)$ in their linear range

Table 1: Absorbance data for calibration curve of TER and ETO

\begin{tabular}{|c|c|c|}
\hline Concentration & Absorbance of TER & Absorbance of ETO \\
\hline 5 & -0.00208 & 0.00952 \\
\hline 10 & -0.00376 & 0.01728 \\
\hline 15 & -0.00566 & 0.02546 \\
\hline 20 & -0.00716 & 0.03392 \\
\hline 25 & -0.00882 & 0.04432 \\
\hline 30 & -0.01094 & 0.05134 \\
\hline
\end{tabular}




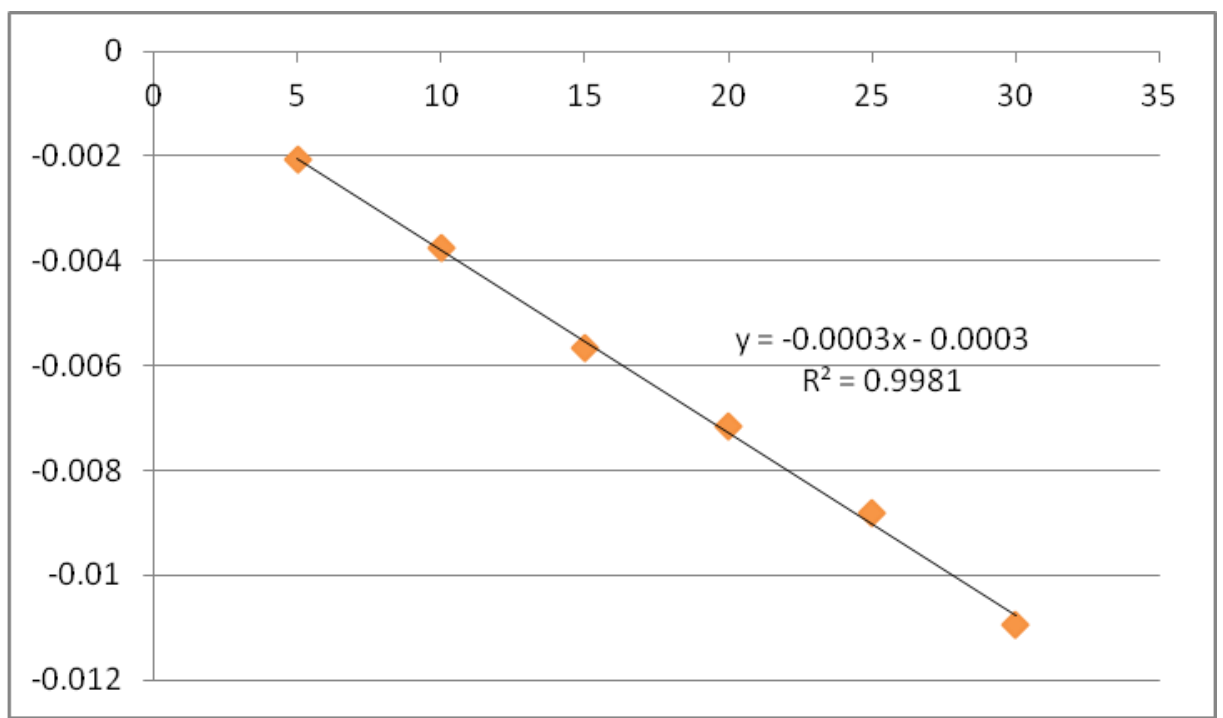

Fig. 4: Calibration graph for TER

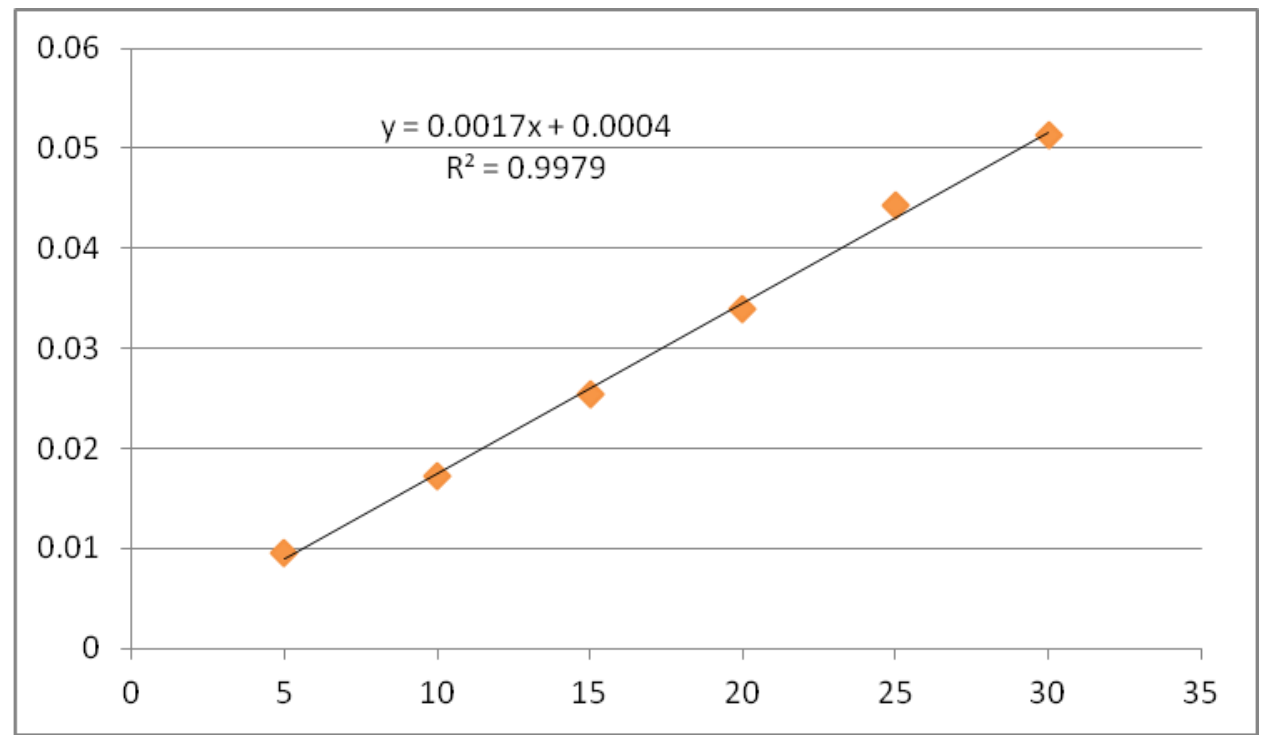

Fig. 5: Calibration graph for ETO

\subsubsection{Analysis of drugs in blend sample (Assay)}

Accurately weighed finely powdered Lactose (150 mg), Magnesium stearate (5 mg) and Starch $(25 \mathrm{mg}$ ) were blended with TER $(20$ $\mathrm{mg}$ ) and ETO (800 $\mathrm{mg}$ ) to form synthetic blend of drugs. For proper and uniform homogenization blend were prepared in large quantities. This blend further used to perform assay and to determine accuracy (recovery study).

www.ijapbjournal.com
The quantity of blend equivalent to $10 \mathrm{mg}$ of TER was weighed, dissolved in $10 \mathrm{ml}$ of methanol and filtered. The $1 \mathrm{ml}$ of filtrate (concentration $1000 \mu \mathrm{g} / \mathrm{ml}$ of TER) was further diluted to $10 \mathrm{ml}$ (concentration 1000 $\mu \mathrm{g} / \mathrm{ml}$ of TER). This Solution was further diluted to get $10 \mu \mathrm{g} / \mathrm{ml}$ of TER. In similar manner dilutions were made to get another solution having concentration $10 \mu \mathrm{g} / \mathrm{ml}$ of ETO. First derivative absorbance spectra of both the solutions were recorded and 
quantification was done through calibration curve. The analysis procedure was repeated six times.

\subsubsection{Accuracy study}

The accuracy of the method was determined by calculating recovery of TER and ETO by the standard addition method. Known amounts of standard solutions of TER and ETO were added at 50, 100 and $150 \%$ level to prequantified sample solutions of both drugs $(10 \mu \mathrm{g} / \mathrm{ml}$ for TER and ETO each). The experiment was repeated for three times.

\subsubsection{Precision}

The precision of the method was demonstrated by intra-day (repeatability) and inter-day (intermediate precision) variation studies. For the intra-day studies, 6 replicates at assay concentrations $(10 \mu \mathrm{g} / \mathrm{ml}$ for TER and ETO each) were analyzed in a day and percentage relative standard deviation (\%RSD) was calculated.

For the inter day variation studies, 3 different concentrations $(5,10$ and $15 \mu \mathrm{g} / \mathrm{ml}$ for both drugs) were analyzed on 3 consecutive days and \% RSD was calculated. The results obtained for intraday (RSD - $0.98 \%$ ) and inter day (RSD - $1.3 \%$ ) variations were found to be within limits (less than 2\% RSD).

\subsubsection{Limit of detection and limit of quantification}

LOD and LOQ were calculated as $3.3 \sigma / \mathrm{S}$ and $10 \sigma / S$, respectively; where $\sigma$ is the standard deviation of the response (y-intercept) and $S$ is the slope of the calibration plot.

\section{RESULTS AND DISCUSSION}

The two drugs can be quantified without separation using first derivative spectroscopy. The wavelengths selected for quantitation were $280 \mathrm{~nm}$ for ETO (zero cross point of TER) and $272.5 \mathrm{~nm}$ for TER (zero cross point of ETO). The results found linear in the range of $5-30 \mu \mathrm{g} / \mathrm{ml}$ for both the drugs. The developed method was found to be accurate, precise and reproducible as results were in limit. Table 2 represents the results of assay performed. The summary of accuracy results is depicted in Table 3. Summary of results is presented in Table 4.

Table 2: Assay of formulation (synthetic mixture prepared in house)

\begin{tabular}{ccccc}
\hline & \multicolumn{2}{c}{ Concentration $(\boldsymbol{\mu g} / \mathbf{m l})$} & \multicolumn{2}{c}{ \% Assay } \\
\cline { 2 - 5 } S. No. & \multirow{2}{*}{ TER } & ETO & $\begin{array}{c}\text { TER } \\
(\mathbf{2 7 2 . 5} \mathbf{~ n m})\end{array}$ & $\begin{array}{c}\text { ETO } \\
(\mathbf{2 8 0} \mathbf{~ n m})\end{array}$ \\
\cline { 2 - 5 } $\mathbf{1}$ & 10 & 10 & 100.42 & 98.64 \\
$\mathbf{2}$ & 10 & 10 & 99.11 & 99.94 \\
$\mathbf{3}$ & 10 & 10 & 98.86 & 100.41 \\
$\mathbf{4}$ & 10 & 10 & 101.2 & 98.89 \\
$\mathbf{5}$ & 10 & 10 & 100.14 & 98.96 \\
$\mathbf{6}$ & 10 & 10 & 101.81 & 99.63 \\
\hline & & Mean & 100.257 & 99.412 \\
& & SD & 1.150 & 0.692 \\
& & RSD & 1.147 & 0.696 \\
\hline
\end{tabular}


Table 3: Accuracy study of TER and ETO by proposed method and their \% RSD

\begin{tabular}{|c|c|c|c|c|c|c|}
\hline \multirow{2}{*}{ Level \% } & \multicolumn{2}{|c|}{ Sample } & \multicolumn{2}{|c|}{ Standard } & \multicolumn{2}{|c|}{$\begin{array}{c}\text { \%Recovery } \\
\pm \% \text { RSD }\end{array}$} \\
\hline & $\begin{array}{c}\text { TER } \\
(\mu \mathrm{g} / \mathrm{ml})\end{array}$ & $\begin{array}{c}\text { ETO } \\
(\mu \mathrm{g} / \mathrm{ml})\end{array}$ & $\begin{array}{c}\text { TER } \\
(\mu \mathrm{g} / \mathrm{ml})\end{array}$ & $\begin{array}{c}\text { ETO } \\
(\mu \mathrm{g} / \mathrm{ml})\end{array}$ & TER & ETO \\
\hline 50 & 10 & 10 & 5 & 5 & $100.873 \pm 0.535$ & $100.890 \pm 1.068$ \\
\hline 100 & 10 & 10 & 10 & 10 & $99.370 \pm 1.028$ & $100.843 \pm 0.930$ \\
\hline 150 & 10 & 10 & 15 & 15 & $100.493 \pm 1.196$ & $99.940 \pm 0.521$ \\
\hline
\end{tabular}

Table 4: Summary of results by proposed first derivative method

\begin{tabular}{ccc}
\hline Parameters & Terbutaline (TER) & Etofylline (ETO) \\
\hline$\lambda$ Determination & $272.5 \mathrm{~nm}$ & $280 \mathrm{~nm}$ \\
(Ist Derivative) & $5-30 \mu \mathrm{g} / \mathrm{ml}$ & $5-30 \mu \mathrm{g} / \mathrm{ml}$ \\
Linearity & & \\
Accuracy & $100.873 \pm 0.535$ & $100.890 \pm 1.068$ \\
$50 \%$ & $99.370 \pm 1.028$ & $100.843 \pm 0.930$ \\
$100 \%$ & $100.493 \pm 1.196$ & $99.940 \pm 0.521$ \\
$150 \%$ & $0.773 \mu \mathrm{g} / \mathrm{ml}$ & $0.121 \mu \mathrm{g} / \mathrm{ml}$ \\
LOD & $2.345 \mu \mathrm{g} / \mathrm{ml}$ & $0.369 \mu \mathrm{g} / \mathrm{ml}$ \\
LOQ & & \\
Precision (\% RSD) & $0.136 \%$ & $0.114 \%$ \\
Intraday & $0.270 \%$ & $0.248 \%$ \\
Interday & $100.257 \pm 1.147$ & $99.412 \pm 0.696$ \\
\% Assay & &
\end{tabular}

\section{CONCLUSION}

Based on the results, obtained from the analysis of described method, it can be concluded that the method has linear response in the range of $5-30 \mu \mathrm{g} / \mathrm{ml}$ for TER and ETO. The results of the analysis of fixed dose combination by the proposed method are reproducible and reliable. The additives usually present in the pharmaceutical formulation of the assayed sample did not interfere with determination of TER and ETO. The method can be used for the routine analysis of these drugs in pharmaceutical formulation.

\section{ACKNOWLEDGEMENT}

Authors are thankful to the Principal, AISSMS college of Pharmacy for providing necessary facilities to carry out the experiment. Authors are also thankful to Himalaya Meditek Pvt. Ltd., Dehradun for providing a reference standard of Etophylline and Terbutaline.

\section{REFERENCES}

[1] http://www.drugs.com/cdi/terbutali ne (accessed on 10/03/2016).

[2] Smith A, Manavalan R, Sridhar K. Spectrophotometric estimation of terbutaline sulphate in pharmaceutical dosage form. IRJP 2010; 1(1): 213-219.

[3] Daraghmeh N, Al-Omari M, Sara Z, Badwan, Jaber A. Determination of terbutaline sulfate and its degradation products in pharmaceutical formulations using LC. J. Pharm. Biomed. Anal., 2002; 29(1): 927-937.

[4] Sunandana B, Sushmitha K, Nalluri B, RP-HPLC-PDA method for the analysis 
of terbutaline sulphate in bulk, dosage forms and in dissolution samples. J. Applied Pharmaceutical Science, 2013; 3(3): 126-132.

[5] http://www.icm.tn.gov.in/drug2520 (accessed on 11/03/2016).

[6] Nirogi R, Kandikere V, Shukla M, Mudigonda K, Ajjala DR A simple and rapid HPLC/UV method for the simultaneous quantification of theophylline and etofylline in human plasma. J Chromatogr $B$ Analyt Technol Biomed Life Sci. 2007; 848(2): 271-276.

[7] Nirav M, Kaushal C. Method development, validation and stability study for simultaneous estimation of etofylline and theophylline by RP-
HPLC chromatography in marketed formulation. J. Chem. Pharm. Res. 2011; 3(3): 597-609.

[8] Garg R, Sharma AK. Simultaneous determination of salbutamol and etofylline by third derivative ultraviolet spectroscopy. Indian J. Pharm. Sci. 1997; 59(6): 295-298.

[9] Indian Pharmacopeia 2007, Indian Pharmacopeia commission. Vol. 3, 1160-1161.

[10] United States pharmacopeia NF 2007, Vol. 30, NF 253292.

\section{How to cite this article:}

Yash S. Nandwani et. al., Development and validation of first order derivative spectrophotometric method for simultaneous estimation of terbutaline and etophylline. Int. J. Adv. Pharm. Biotech., 2017; 3(1): 1-7. 